TITLE:

\title{
Experimental Study on Powder Flowability Using Vibration Shear Tube Method
}

\section{$\operatorname{AUTHOR(S):~}$}

Zainuddin, Imran M.; Yasuda, Masatoshi; Horio, Takehiko; Matsusaka, Shuji

\section{CITATION:}

Zainuddin, Imran M....[et al]. Experimental Study on Powder Flowability Using Vibration Shear Tube Method. Particle \& Particle Systems Characterization 2012, 29(1): 8-15

\section{ISSUE DATE:}

2012-05

URL:

http://hdl.handle.net/2433/229116

\section{RIGHT:}

This is the accepted version of the following article: [Zainuddin, I. M., Yasuda, M., Horio, T. and Matsusaka, S. (2012), Experimental Study on Powder Flowability Using Vibration Shear Tube Method. Part. Part. Syst. Charact., 29: 8-15], which has been published in final form at https://doi.org/10.1002/ppsc.201100052. This article may be used for noncommercial purposes in accordance with Wiley Terms and Conditions for Self-Archiving.; The full-text file will be made open to the public on 22 MAY 2013 in accordance with publisher's 'Terms and Conditions for Self-Archiving'; この論文は 出版社版でありません。引用の際には出版社版をご確認ご利用ください。; This is not the published version. Please cite only the published version. 


\title{
Original Paper for Particle \&Particle Systems Characterization
}

\section{Experimental Study on Powder Flowability Using Vibration Shear Tube Method}

\author{
M. Imran Zainuddin*, Masatoshi Yasuda*,**, Takehiko Horio**, Shuji Matsusaka**
}

\begin{abstract}
The flowability of powders with different mass median diameters ranging from micrometers to nanometers was measured using the vibration shear tube method. In the measurement system used in this study, the powder was discharged through a narrow gap between a vibrating tube edge and a flat bottom surface, where each particle could experience high shear forces to overcome the adhesion and friction forces. The vibration amplitude was increased during the measurement, and the mass of particles discharged was measured at constant time intervals. From the relationship between the mass flow rate and the vibration acceleration, static and dynamic properties of the powders were evaluated using the critical vibration acceleration, characteristic mass flow rate, and gradient of mass flow rate. The correlation between the static and dynamic properties was studied in detail.
\end{abstract}

Keywords: flowability, measurement, vibration, shear

* Dr. M. Imran Zainuddin, Masatoshi Yasuda, IMP, 67-20 Ichibu-cho, Ikoma-shi, Nara 630-0222 (Japan).

** Masatoshi Yasuda, Takehiko Horio, Prof. Shuji Matsusaka (corresponding author), Department of Chemical Engineering, Kyoto University, Kyoto 615-8510 (Japan).

E-mail: matsu@cheme.kyoto-u.ac.jp 


\section{Introduction}

Powders are widely used in various applications involving numerous powder handling operations, such as storage, feeding, transport, mixing, fluidization, and granulation. In order to properly perform these operations, it is essential to understand the behavior of particles in each unit operation. In general, powder flowability is considered to be a key property in evaluating the stability of a process $[1,2]$. The flowability is also important for the development of new materials and quality control of products as well as for process control.

Much effort has been made to theoretically estimate powder flowability; however, the estimation is very difficult because there are too many factors. For example, particle size, shape, surface roughness and density are well known factors [3-5]. Furthermore, the surrounding conditions such as temperature and humidity also affect the flowability $[6,7]$. Therefore, the most practical way to evaluate the powder flowability is to conduct experimental tests.

In past decades, various evaluation methods have been developed and widely used, e.g. Carr's method [8], Jenike shear tester [9, 10], and Hall flowmeter [11]. However, these methods have some disadvantages [12]. Some of them are difficult to carry out, and are not suitable in terms of stress state. To counter these problems, a ring shear tester [13], an avalanche method [14], a vibratory feeder method [15], a vibrating capillary method [16-20], a twisted blade method [21], and an indentation method [22] were proposed.

It is important to use methods appropriate for the actual operation. In fact, particle behavior greatly depends on the state. For example, particles in a hopper are in a static state if the particles are settled and there is no motion; however, particles in feeding are in a dynamic state. Therefore, the evaluation of the critical condition to enable particle flow that is related to static friction, and the evaluation of the mass flow rate related to dynamic friction is important in designing equipment and controlling processes. Krantz et al. [23] mentioned that it is inappropriate to extend the results obtained from a static evaluation method to a dynamic process and also from a dynamic evaluation method to a static process. 
The vibrating capillary method can give the critical vibration acceleration that results in a powder flow, with the mass flow rate modeled as a function of vibration acceleration, hysteresis, and stability of the powder flow [17]. The critical vibration acceleration is related to the static friction and the adhesiveness of particles and the mass flow rate is related to the dynamic friction of particles [19]; therefore, static and dynamic properties in powder flowability can be evaluated. This method uses a tube with a narrow opening to evaluate a small powder flow. As a result, the flow sensitivity is high; however, particle bridging will occur within the capillary when adhesion forces between particles are too high. This will hinder powder flow and disturb the measurement. To solve this problem and to increase measurement capability, the vibration shear tube method has been designed [24]. The measurement system consists of a vibrating tube and a bottom surface. The vibration can be transferred directly to the particles in the narrow gap between the vibrating tube edge and the flat bottom surface; thus, the particles experience high shear forces that help overcome the adhesion and friction forces. This method is expected to be useful for highly adhesive particles including nanoparticles. In addition, the powder state in this system is changed from static to dynamic by increasing vibration amplitude; thus, both the static and dynamic properties in powder flowability can be evaluated. In the previous study [24], the basic performance of this system was evaluated with alumina particles that had mass median diameters of $2-60 \mu \mathrm{m}$.

In this study, we measure the flowability of various powders with mass median diameters ranging from micrometers to nanometers using the vibration shear tube method, and experimentally verify the performance. Furthermore, we discuss the static and dynamic properties in detail.

\section{Experimental}

Micropowders and nanopowders used in the experiment are shown in Table $\mathbf{1}$ and Table 2, 
respectively. The names of the samples are abbreviated, e.g., white fused alumina with a mass median diameter of $2 \mu \mathrm{m}$ is abbreviated as A (2). All the samples were dried at a temperature of $120{ }^{\circ} \mathrm{C}$ for $24 \mathrm{~h}$ and stored in a dessicator at a relative humidity of about $30 \%$, and the measurements of flowability were carried out at a room temperature of $25 \pm 2{ }^{\circ} \mathrm{C}$ and a relative humidity of $40 \pm 5 \%$.

Figure 1 shows a schematic diagram of the experimental setup, which is the same as that used in the previous study [24]. The measurement section consists of a glass tube, a bottom made of metal, and a piezoelectric vibrator. The glass tube, $200 \mathrm{~mm}$ long, $8 \mathrm{~mm}$ in inner diameter, $10 \mathrm{~mm}$ in outer diameter, and $0.46 \mu \mathrm{m}$ in average surface roughness of the tube edge, was held vertically, and the bottom, $10 \mathrm{~mm}$ in diameter and $0.38 \mu \mathrm{m}$ in average surface roughness, was placed below the tube with a narrow gap. The gap distance $h$, which is the width of the outlet slit for powder discharge, can be varied manually by means of a screw micrometer. In this experiment, the gap distance was set at $0.6 \mathrm{~mm}$. The piezoelectric vibrator was fixed to the tube at a height of $50 \mathrm{~mm}$ from the bottom end of the tube. Relative movement in the gap occurs due to the horizontal vibration of the tube. The vibration amplitude was measured at a height of $10 \mathrm{~mm}$ from the bottom edge using a laser vibrometer and controlled by a feedback system (VST-01 Control system, IMP. Co. Ltd.), so as to increase at a constant rate of $0.5 \mu \mathrm{m} / \mathrm{s}$ up to $100 \mu \mathrm{m}$; thus, the measurement time was $200 \mathrm{~s}$. The vibration acceleration $\alpha$ was calculated by

$$
\alpha=A(2 \pi f)^{2}
$$

where $A$ is the vibration amplitude and $f$ is the frequency. In this system, the frequency was fixed at $300 \mathrm{~Hz}$ so as to maximize the vibration amplitude due to resonance. Therefore, the increasing rate of the vibration acceleration $\mathrm{d} \alpha / \mathrm{d} t$ was $1.8 \mathrm{~m} / \mathrm{s}^{3}$. A digital balance with a resolution of $0.1 \mathrm{mg}$ and a response time of $1 \mathrm{~s}$ was used to measure the mass of particles discharged. The data was recorded in the computer at intervals of 1 or $4 \mathrm{~s}$.

Powder was filled into the tube through a removable funnel, and a pretest under vibration 
was carried out to fill it uniformly; then the measurement was repeated 8 times under the same conditions. The amount of powder required for the repeated measurements was about $2-40 \mathrm{~g}$, depending on the particle packing density under vibration. The height of the powder bed in the tube was more than $160 \mathrm{~mm}$ during the measurement. For the flowability analysis, the mean and standard error of the mean, which is the standard deviation divided by the square root of the number of measurements, were taken into consideration.

\section{Results and discussion}

\subsection{Powder flowability profile}

Figure 2 (a) shows the mass of particles measured at intervals of $4 \mathrm{~s}$. These results were obtained under the condition where the vibration acceleration increased linearly with time for $200 \mathrm{~s}$ (Fig. 2 (b)). For no or low vibration, the downward particle flow due to gravity in the tube is prevented by cohesive arching and the static friction against the vertical wall as well as with the flat bottom surface. Also, the horizontal flow in the gap is prevented by the static friction against the surrounding walls. As the horizontal vibration acceleration increases, a small clearance develops between the vertical wall and the powder bed; thus, the wall friction will be reduced $[25,26]$ and the powder bed can move downward due to gravity. In the gap, a shear field is generated by the vibration of the tube. As a result, adhesion forces between particles are overcome by forces generated in the shear field. In other words, the vibration causes the particles to lose contact and flow out of the outlet slit by the powder pressure under gravity. The mass flow rate is controlled by the horizontal particle flow in the gap.

In order to evaluate the flowability in more detail, the relationship between the mass flow rate and the vibration acceleration, i.e. the flowability profile, should be analyzed. The figures $\mathbf{3}$ (a)-(d) show the flowability profiles obtained from the results in Figure 2. The flowability profiles are separated into four groups for clarity. The mass flow rate increases with the vibration after exceeding a certain value of critical vibration acceleration. A typical dependence 
of particle diameter on powder flowability can be seen in Figure 3 (a); however, powder flowability cannot be estimated only by the particle diameter but also by material characteristics such as shape, surface roughness, density, etc. In addition, it is interesting to compare the stability of the flowability profiles. The error bars in Figure 3 are generally small and the repeatability of the data is found to be excellent. Among all of them, the error bars for flyash are rather large. The repeatability may indicate a feature of powder flowability.

Figure 4 shows the procedures to determine the values to evaluate the static and dynamic properties related to the static and dynamic frictions of particles, respectively. The flow state around critical vibration acceleration to enable particle flow may not always be clear; thus, a threshold is needed to evaluate the static properties. The mass flow rate of $2 \mathrm{mg} / \mathrm{s}$ was chosen as the threshold $w_{\mathrm{c}}$, and the critical vibration acceleration $\alpha_{\mathrm{c}}$ was determined for the corresponding vibration acceleration. To evaluate the dynamic properties, a characteristic mass flow rate $w_{\alpha}$ at a given vibration acceleration was introduced. Here, a value of $300 \mathrm{~m} / \mathrm{s}^{2}$ was chosen as the vibration acceleration, at which a stable powder flow was observed for all the samples. Another value was also introduced to evaluate the dynamic properties; this value is defined as the gradient of mass flow rate. The value was determined by line-fitting the increasing slope of the flowability profile. Although the gradient of mass flow rate is an important factor for evaluating the dynamic properties, the procedure is somewhat tedious compared to that used in evaluating the characteristic mass flow rate.

\subsection{Static and dynamic properties of powder}

Figure 5 shows the critical vibration acceleration $\alpha_{\mathrm{c}}$ as a function of the mass median diameter $D_{\mathrm{p} 50}$. The critical vibration acceleration to enable particle flow is related to the static friction of the particles; thus, a lower value of the critical vibration acceleration indicates higher flowability. The critical vibration acceleration decreases with increasing mass median diameter $\left(D_{\mathrm{p} 50} \leq 15 \mu \mathrm{m}\right)$. In particular, the variation is more significant at a smaller mass median diameter. Fine particles tend to agglomerate due to adhesion forces; hence, higher vibration acceleration is 
required to disintegrate the agglomerates and to discharge the particles from the outlet slit. Therefore, this evaluation method provides information about the relationship of flowability to the strength of the agglomerates. Differences in static properties due to the material characteristics can also be seen in this figure. For example, where the mass median diameter is around $5 \mu \mathrm{m}$, talc shows the highest flowability, followed by flyash, kanto loam, and alumina. Calcium carbonate shows the lowest flowability. This result provides an evaluation of the effect of the material on the static properties.

Figure 6 shows the characteristic mass flow rate $w_{\alpha}$ as a function of the mass median diameter $D_{\mathrm{p} 50}$. The characteristic mass flow rate increases with increasing mass median diameter. The movement of particles during flow is restricted by the dynamic friction of the particles; hence, a high characteristic mass flow rate indicates a low dynamic friction, i.e. high flowability. Therefore, this result shows that the dynamic flowability increases with increasing mass median diameter. The differences in dynamic flowability can also be seen in materials. On the whole, Silica shows the highest flowability, followed by alumina, kanto loam, flyash, and talc. Calcium carbonate shows the lowest flowability. This result provides an evaluation of the effect of material on the dynamic properties. Calcium carbonate also had the lowest flowability when measured as a static property as shown in Fig. 5. Talc has the highest flowability in the static state; however, the flowability in the dynamic state is not so high. Therefore, a high flowability in the static state does not ensure a high flowability in the dynamic state; hence the static and dynamic properties should be evaluated separately.

Figure 7 shows the relationship between the characteristic mass flow rate and the critical vibration acceleration. The characteristic mass flow rate decreases with increasing critical vibration acceleration for the same material. This result shows that the dynamic properties are generally correlated with the static properties. However, for different materials, even though the static properties are similar to each other, their dynamic properties can be greatly different. Conversely, it is also true that even though the dynamic properties are similar to each other, 
their static properties can be greatly different.

Another factor for evaluating the dynamic properties is the gradient of mass flow rate, i.e. the increasing slope of the flowability profile. Figure $\mathbf{8}$ shows the gradient of the mass flow rate as a function of the mass median diameter. The gradient tends to increase with increasing mass median diameter. This variation is similar to that shown by the characteristic mass flow rate (see Figure 6).

Figure 9 shows the relationship between the gradient of the mass flow rate and the characteristic mass flow rate. The gradient of the mass flow rate increases with increasing characteristic mass flow rate. This result clearly shows that there is a positive correlation between the two variables. Although the gradient of the mass flow rate can be an important factor for evaluating the dynamic flowability, the line fitting that has to be done to obtain the value is somewhat tedious. Therefore, the critical vibration acceleration is convenient for a simple evaluation of the dynamic properties.

Figure 10 shows the relationship between the gradient of the mass flow rate and the critical vibration acceleration. As was expected, a negative correlation was seen between them. This variation is similar to that shown in Fig. 7.

\subsection{Flowability profiles of nanopowders}

Figure 11 shows the flowability profiles of fumed silica nanopowders. The values obtained at intervals of $1 \mathrm{~s}$ in the measurement of $120 \mathrm{~s}$ are plotted. The vibration acceleration was increased up to $220 \mathrm{~m} / \mathrm{s}^{2}$. The maximum vibration acceleration was reduced compared to that for micrometer sized particles. This is because when using nanopowders, a blockage occurs at high vibration accelerations.

The flowability profiles show that the mass flow rate increases with increasing vibration acceleration after exceeding a certain value of critical vibration acceleration. These features are similar to those for micrometer sized particles. However, the values of mass flow rate of nanopowders are very small. In order to evaluate the flowability, the values of the critical 
vibration acceleration, the characteristic mass flow rate, and the gradient of mass flow rate obtained from the flowability profiles are summarized in Table 3. The differences in their flowability profiles are caused by the surface treatment (see Table 2). FS0 $\left(D_{\mathrm{p}}=40 \mathrm{~nm}\right.$ ) is an untreated powder, and the hydrophilic particle surface attracts moisture; thus the interparticle forces are rather large. As a result, FS0 did not flow continuously during the measurement. FS1 is changed from hydrophilic to hydrophobic by the surface treatment of FS0 with hexamethyldisilazane (HMDS). Its flowability is improved due to low moisture adsorption. FS2 has the same surface property as FS1; however, the particle diameter is small $\left(D_{\mathrm{p}}=12 \mathrm{~nm}\right)$. FS2 shows higher flowability compared to FS1. This fact may be surprising because smaller mass median diameters generally reduce the flowability. The improvement of the flowability may be attributed to the loose particle network, i.e. low bulk density. This inference can be supported by the following facts: FS3 has the same treatment as FS2 but the powder bulk density is rather high due to disintegration of aggregates by mechanical after-treatment (see Table 2). As a result, the flowability of FS3 might have been lower than that of FS2 and similar to FS1. FS4 is treated with polydimethylsiloxane (PDMS, silicone oil). The oily substance on the surface might have raised the interparticle forces and reduced the flowability even though the bulk density was rather low.

\section{Conclusion}

The flowability of powders with different mass median diameters was evaluated experimentally. The mass median diameters were in the range of $12 \mathrm{~nm}-60 \mu \mathrm{m}$, and the test method was the vibration shear tube method. The powder was discharged through the narrow gap between the vibrating tube edge and the flat bottom surface by increasing the vibration acceleration with time at a constant rate. The mass flow rate and the vibration acceleration were obtained at constant intervals.

From the relationship between the mass flow rate and the vibration acceleration, the static 
and dynamic properties of the powders were evaluated. The critical vibration acceleration to enable particle flow was analyzed in order to evaluate the static properties. The characteristic mass flow rate at a given vibration acceleration and the gradient of mass flow rate were analyzed for evaluating the dynamic properties.

The effects of mass median diameter and material characteristics on the static and dynamic properties were studied, showing that the dynamic properties were generally correlated with the static properties; however, these values varied according to the material. Therefore, even though the static properties are similar to each other, their dynamic properties may be greatly different if using different materials. Conversely, even though the dynamic properties are similar to each other, their static properties may be greatly different; hence, the static and dynamic properties should be evaluated separately.

The flowability of nanopowders with different surface treatment was also successfully evaluated. The vibration shear tube method was applicable for a wide range of powders including highly adhesive powders.

\section{Acknowledgements}

The authors acknowledge the financial support from the Information Center of Particle Technology, Japan. This research was also supported by a Grant no. S0901039 from MEXT, Japan and the program to promote a career path for research personnel of academia and accelerate technology transfer, JST. The authors are thankful to Evonik industries for providing nanopowders.

\section{References}

[1] J. K. Prescott, R. A. Barnum, On Powder Flowability. Pharm. Technol. 2000, 24, 60-84.

[2] J. Schwedes, Review on Testers for Measuring Flow Properties of Bulk Solids, Granul. Matter. 2003, 5, 1-43. 
[3] A. Guo, J. K. Beddow, A. F. Vetter, A Simple Relationship between Particle Shape Effects and Density, Flow Rate and Hausner Ratio. Powder Technol. 1985, 43, 279-284.

[4] D. Geldart, E.C. Abdullah, A. Verlinden, Characterisation of Dry Powders. Powder Technol. 2009, 190, 70-74.

[5] W. Yu, K. Muteki, L. Zhang, G. Kim, Prediction of Bulk Powder Flow Performance Using Comprehensive Particle Size and Particle Shape Distributions. J. Pharm. Sci. 2011, 100, 284-293.

[6] E. Teunou, J. J. Fitzpatrick, E. C. Synnott, Characterisation of Food Powder Flowability. $J$. Food Eng. 1999, 39, 31-37.

[7] J. J. Fitzpatrick, M. Hodnett, M. Twomey, P. S. M. Cerqueira, J. O'Flynn, Y. H. Roos, Glass Transition and the Flowability and Caking of Powders Containing Amorphous Lactose. Powder Technol. 2007, 178, 119-128.

[8] R. L. Carr, Evaluating Flow Properties of Solids. Chem. Eng. 1965, January 18, 163-168.

[9] A. W. Jenike, Gravity Flow of Bulk Solids. Bulletin No. 108, Utah Engineering Experiment Station, Univ. of Utah. 1961.

[10] ASTM D6128-06 Standard Test Method for Shear Testing of Bulk Solids Using the Jenike Shear Cell. 2006.

[11] ISO4490 Metallic Powders-Determination of Flow Time by Means of a Calibrated Funnel (Hall Flowmeter) 2008.

[12] D. Schulze, Powders and Bulk Solids: Behavior, Characterization, Storage and Flow. Springer, New York, 2008.

[13] ASTM D6773-08 Standard Test Method for Bulk Solids Using Schulze Ring Shear Tester. 2008.

[14] F. Lavoie, L. Cartilier, R. Thibert, New Methods Characterizing Avalanche Behavior to Determine Powder Flow. Pharm. Res. 2002, 19, 887-893.

[15] S. N. Bhattachar, D. B. Hedden, A. M. Olsofsky, X. Qu, W.-Y. Hsieh, K. G. Canter, 
Evaluation of the Vibratory Feeder Method for Assessment of Powder Flow Properties. 2004, Int. J. Pharm., 269, 385-392.

[16] Y. Jiang, S. Matsusaka, H. Masuda, T. Yokoyama, Evaluation of Flowability of Composite Particles and Powder Mixtures by a Vibrating Capillary Method. J. Chem. Eng. Japan. 2006, 39, 14-21.

[17] Y. Jiang, S. Matsusaka, H. Masuda, Y. Qian, Development of Measurement System for Powder Flowability Based on Vibrating Capillary Method. Powder Technol. 2009, 188, 242-247.

[18] K. Ishii, M. Suzuki, T. Yamamoto, Y. Kihara, Y. Kato, T. Kurita, K. Yoshimoto, M. Yasuda, S. Matsusaka, Flowability Measurement of Coarse Particles Using Vibrating Tube Method. J. Chem. Eng. Jpn. 2009, 42, 319-324.

[19] K. Ishii, M. Suzuki, T. Segawa, Y. Kihara, M. Yasuda, S. Matsusaka, Flowability Measurement of Pulverized and Granulated Materials Using Vibrating Tube Method, Advanced Powder Technol. 2011, 22, 319-323.

[20] K. Ishii, M. Suzuki, T. Segawa, Y. Kihara, M. Yasuda, S. Matsusaka, A Vibrating Tube Method for Evaluating Flowability of a Small Amount of Sample Particles, Advanced Powder Technol. 2011, 22, 522-525.

[21] R. Freeman, Measuring the Flow Properties of Consolidated, Conditioned and Aerated Powders - A Comparative Study Using a Powder Rheometer and a Rotational Shear Cell. Powder Technol. 2007, 174, 25-33.

[22] A. Hassanpour, M. Ghadiri, Characterisation of Flowability of Loosely Compacted Cohesive Powders by Indentation. Part. Part. Syst. Char. 2007, 24, 117-123.

[23] M. Krantz, H. Zhang, J. Zhu, Characterization of Powder Flow: Static and Dynamic Testing. Powder Technol. 2009, 194, 239-245.

[24] M. Imran Zainuddin, M. Yasuda, Y.-H., Liu, H. Maruyama, S. Matsusaka, Development of Vibration Shear Tube Method for Powder Flowability Evaluation, Powder Technol. 2012, 
$217,548-553$.

[25] S. Matsusaka, M. Urakawa, H. Masuda, Micro-feeding of Fine Powders Using Capillary Tube with Ultrasonic Vibration. Advanced Powder Technol. 1995, 6, 283-293.

[26] S. Matsusaka, K. Yamamoto, H. Masuda, Micro-feeding of a Fine Powder Using a Vibrating Capillary Tube. Advanced Powder Technol. 1996, 7, 141-151. 


\section{List of Figures}

Fig. 1: Schematic diagram of the experimental setup.

Fig. 2: Mass of the particles discharged $W$ (upper) and vibration acceleration $\alpha$ (lower) as a function of time elapsed.

Fig. 3: Flowability profiles of (a) white fused alumina, (b) silica sand and talc, (c) kanto loam, (d) flyash and calcium carbonate, heavy.

Fig. 4: An example to determine critical vibration acceleration $\alpha_{\mathrm{c}}$ and characteristic mass flow rate $w_{a}$ and gradient of mass flow rate $\mathrm{d} w / \mathrm{d} \alpha$ (flowability profile of $\left.\mathrm{A}(15)\right)$.

Fig. 5: Critical vibration acceleration as a function of the mass median diameter.

Fig. 6: Characteristic mass flow rate as a function of the mass median diameter.

Fig. 7: Relationship between the characteristic mass flow rate and the critical vibration acceleration.

Fig. 8: Gradient of the mass flow rate as a function of the mass median diameter.

Fig. 9: Relationship between the gradient of the mass flow rate and the characteristic mass flow rate.

Fig. 10: Relationship between the gradient of the mass flow rate and the critical vibration acceleration.

Fig. 11: Flowability profiles of fumed silica nanopowders. 
Table 1: Properties of various micropowders.*

\begin{tabular}{|c|c|c|c|c|c|}
\hline Sample & $D_{\mathrm{p} 50}(\mu \mathrm{m})^{* *}$ & $\begin{array}{c}\text { Powder bulk } \\
\text { density }\left(\mathrm{kg} / \mathrm{m}^{3}\right)\end{array}$ & $\begin{array}{c}\text { Particle density } \\
\left(\mathrm{kg} / \mathrm{m}^{3}\right)\end{array}$ & Material & Shape \\
\hline$A(2)$ & 2 & 980 & \multirow{6}{*}{4000} & \multirow{6}{*}{ White fused alumina } & \multirow{6}{*}{ Irregular } \\
\hline $\mathrm{A}(4)$ & 4 & 1230 & & & \\
\hline $\mathrm{A}(8)$ & 8 & 1570 & & & \\
\hline $\mathrm{A}(15)$ & 15 & 1850 & & & \\
\hline $\mathrm{A}(31)$ & 31 & 2120 & & & \\
\hline $\mathrm{A}(60)$ & 60 & 2220 & & & \\
\hline $\mathrm{S}(8)$ & 8 & 870 & \multirow{2}{*}{2700} & \multirow{2}{*}{ Silica sand } & \multirow{2}{*}{ Irregular } \\
\hline $\mathrm{S}(28)$ & 28 & 1250 & & & \\
\hline $\mathrm{T}(4)$ & 4 & 240 & \multirow{2}{*}{2800} & \multirow{2}{*}{ Talc } & \multirow{2}{*}{ Platy } \\
\hline $\mathrm{T}(8)$ & 8 & 410 & & & \\
\hline $\mathrm{K}(2)$ & 2 & 580 & \multirow{3}{*}{2900} & \multirow{3}{*}{ Kanto loam } & \multirow{3}{*}{ Irregular } \\
\hline $\mathrm{K}(7)$ & 7 & 890 & & & \\
\hline$K(29)$ & 29 & 910 & & & \\
\hline$F(5)$ & 5 & 690 & \multirow{2}{*}{2300} & \multirow{2}{*}{ Flyash } & \multirow{2}{*}{ Spherical } \\
\hline $\mathrm{F}(15)$ & 15 & 990 & & & \\
\hline $\mathrm{C}(2)$ & 2 & 580 & \multirow{2}{*}{2700} & \multirow{2}{*}{ Calcium carbonate, heavy } & \multirow{2}{*}{ Irregular } \\
\hline $\mathrm{C}(4)$ & 4 & 710 & & & \\
\hline
\end{tabular}

* JIS Z 8901, ** mass median diameter.

Table 2: Properties of fumed silica nanopowders.

\begin{tabular}{cccl}
\hline Sample & $D_{\mathrm{p}}(\mathrm{nm}) *$ & Powder bulk density $\left(\mathrm{kg} / \mathrm{m}^{3}\right) * *$ & \multicolumn{1}{c}{ Description } \\
\hline FS0 & 40 & 130 & $\begin{array}{l}\text { Hydrophilic, no surface treatment } \\
\text { Hydrophobic, surface treatment with } \\
\text { hexamethyldisilazane, HMDS } \\
\text { FS1 }\end{array}$ Hydrophobic, surface treatment with $^{\text {HMDS }}$ \\
FS2 & 12 & 170 & $\begin{array}{l}\text { Hydrophobic, surface treatment with } \\
\text { HMDS \& disintegration of aggregates } \\
\text { Hydrophobic, surface treatment with } \\
\text { polydimethylsiloxane, PDMS }\end{array}$ \\
\hline
\end{tabular}

* nominal particle diameter, ** Particle density: $2200 \mathrm{~kg} / \mathrm{m}^{3}$.

Table 3: Characteristic values based on flow profiles of fumed silica nanopowders.

\begin{tabular}{cccc}
\hline Sample & $a_{\mathrm{c}}\left(\mathrm{m} / \mathrm{s}^{2}\right)^{*}$ & $w_{\mathrm{a}}(\mathrm{mg} / \mathrm{s})^{* *}$ & $\mathrm{~d} w / \mathrm{d} \alpha(\mu \mathrm{g} \cdot \mathrm{s} / \mathrm{m})$ \\
\hline FS0 & - & 0 & 0 \\
FS1 & 70 & 0.9 & 6 \\
FS2 & 79 & 2.1 & 32 \\
FS3 & 98 & 0.9 & 8 \\
FS4 & 142 & 0.5 & 5 \\
\hline
\end{tabular}

* Mass flow rate: $0.2 \mathrm{mg} / \mathrm{s}$, ** vibration acceleration: $200 \mathrm{~m} / \mathrm{s}^{2}$. 


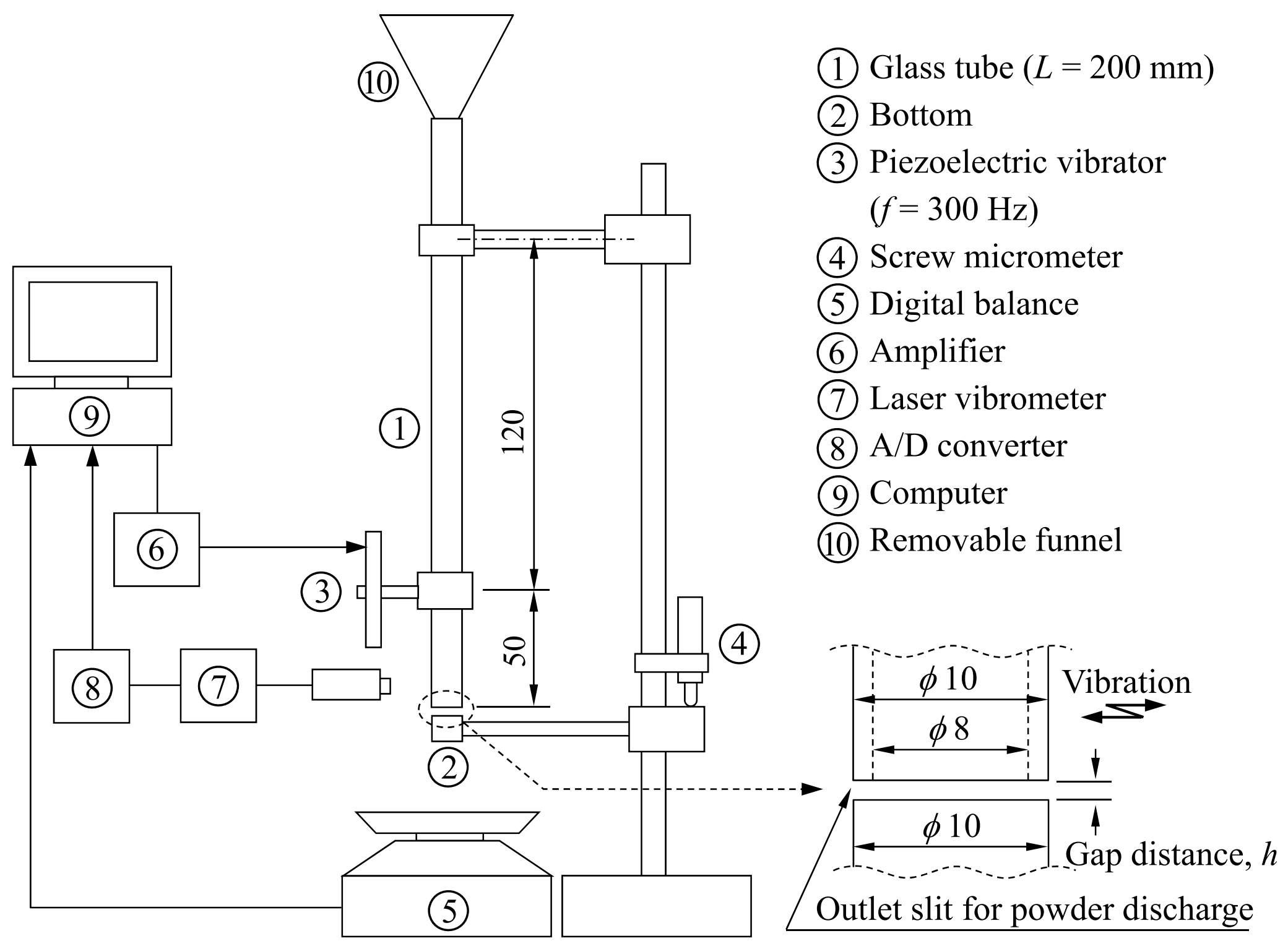

Fig. 1: Schematic diagram of the experimental setup. 

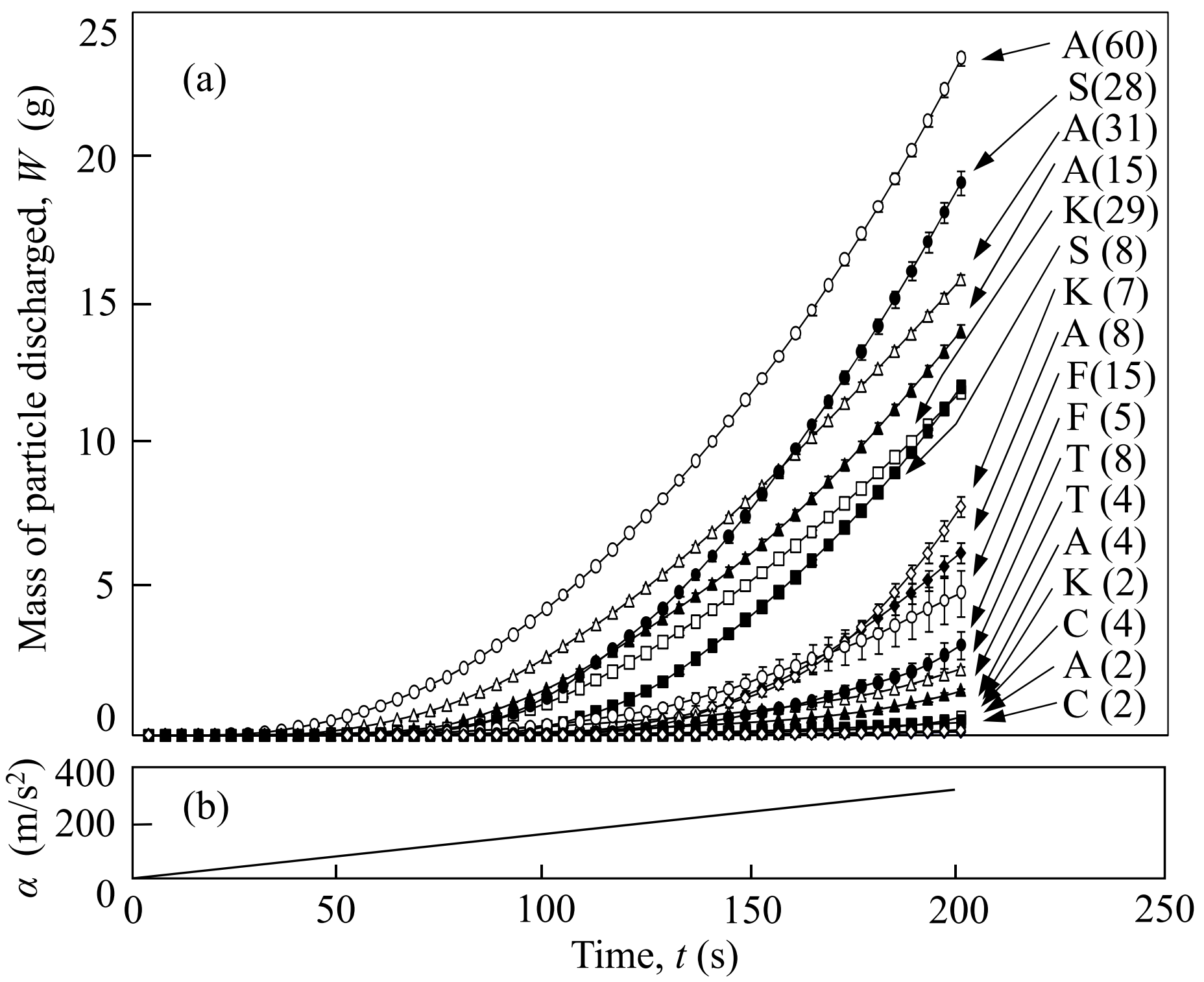

Fig.2: Mass of the particles discharged $W$ (upper) and vibration acceleration $\alpha$ (lower) as a function of time elapsed. 


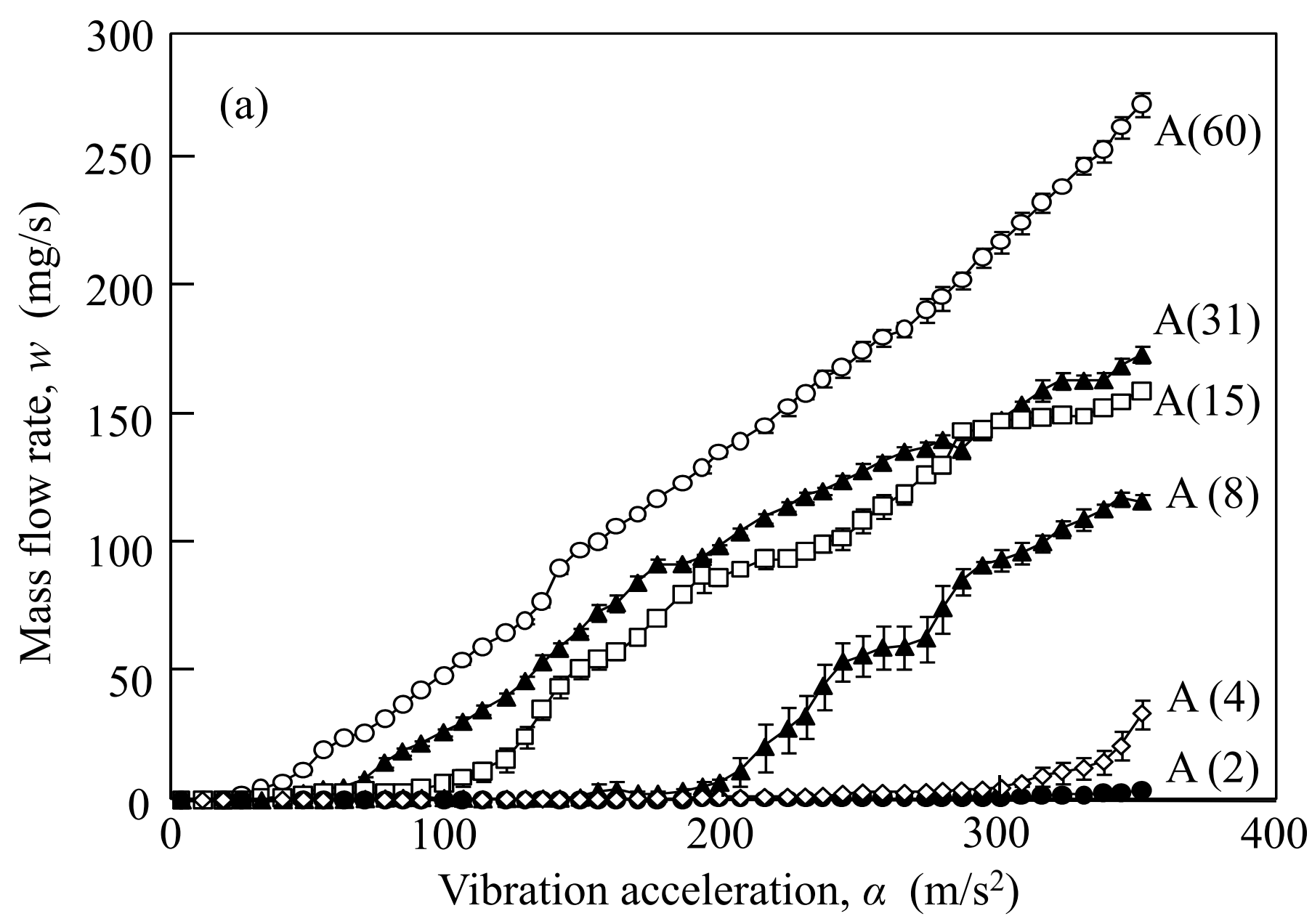

Fig.3: Flowability profiles of (a) white fused alumina, (b) silica sand and talc, (c) kanto loam, (d) flyash and calcium carbonate, heavy. 


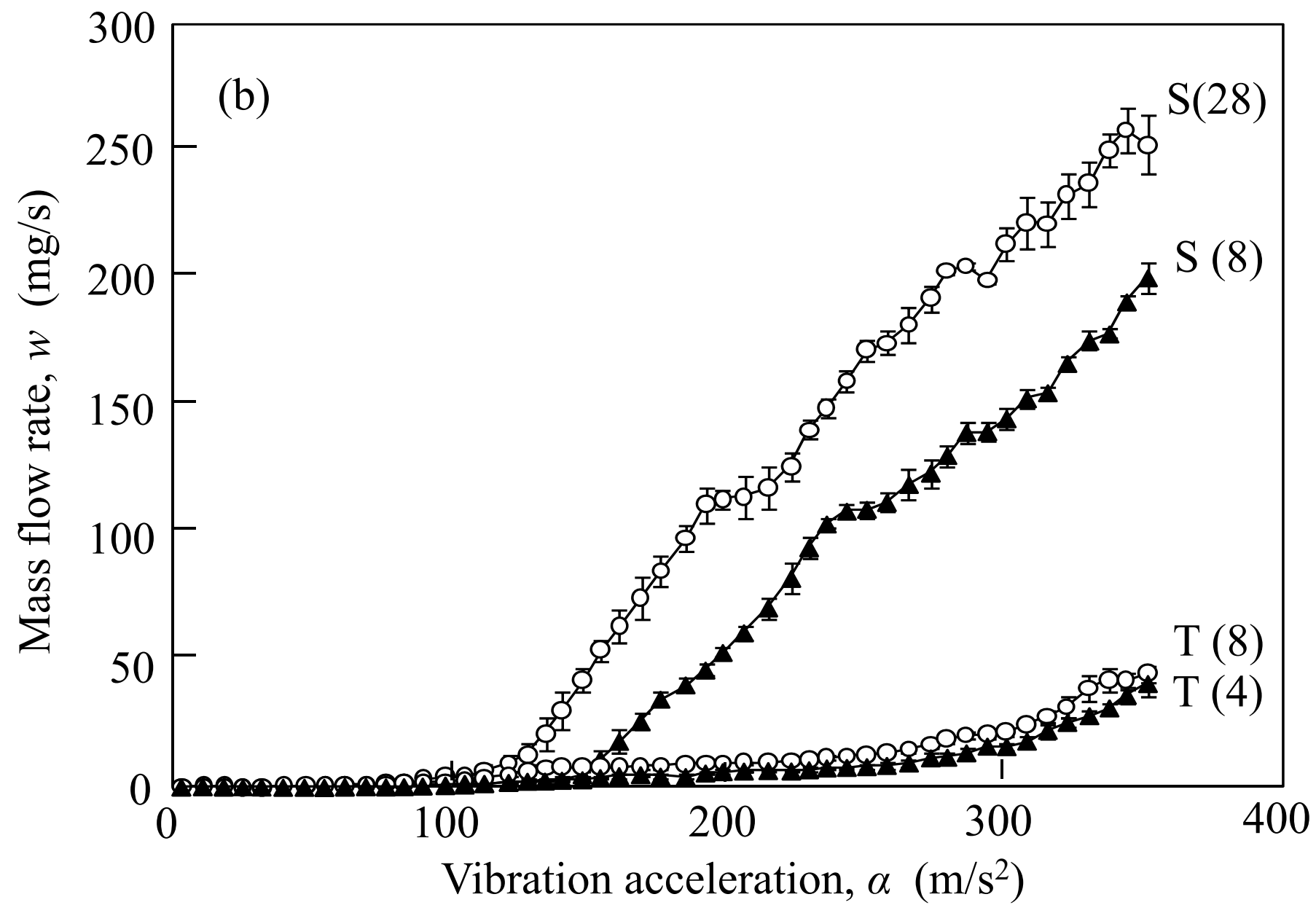

Fig.3: 


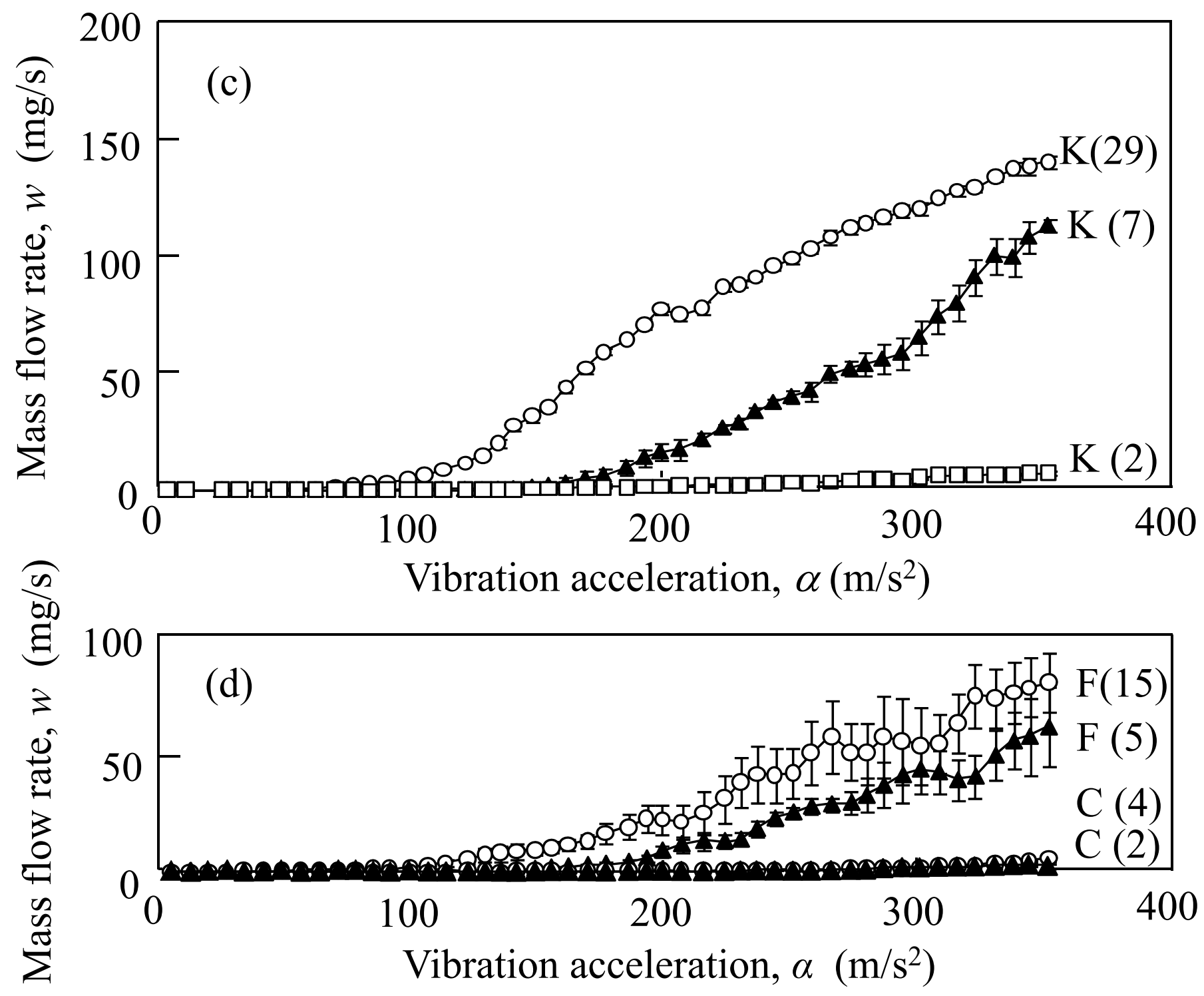

Fig.3: 


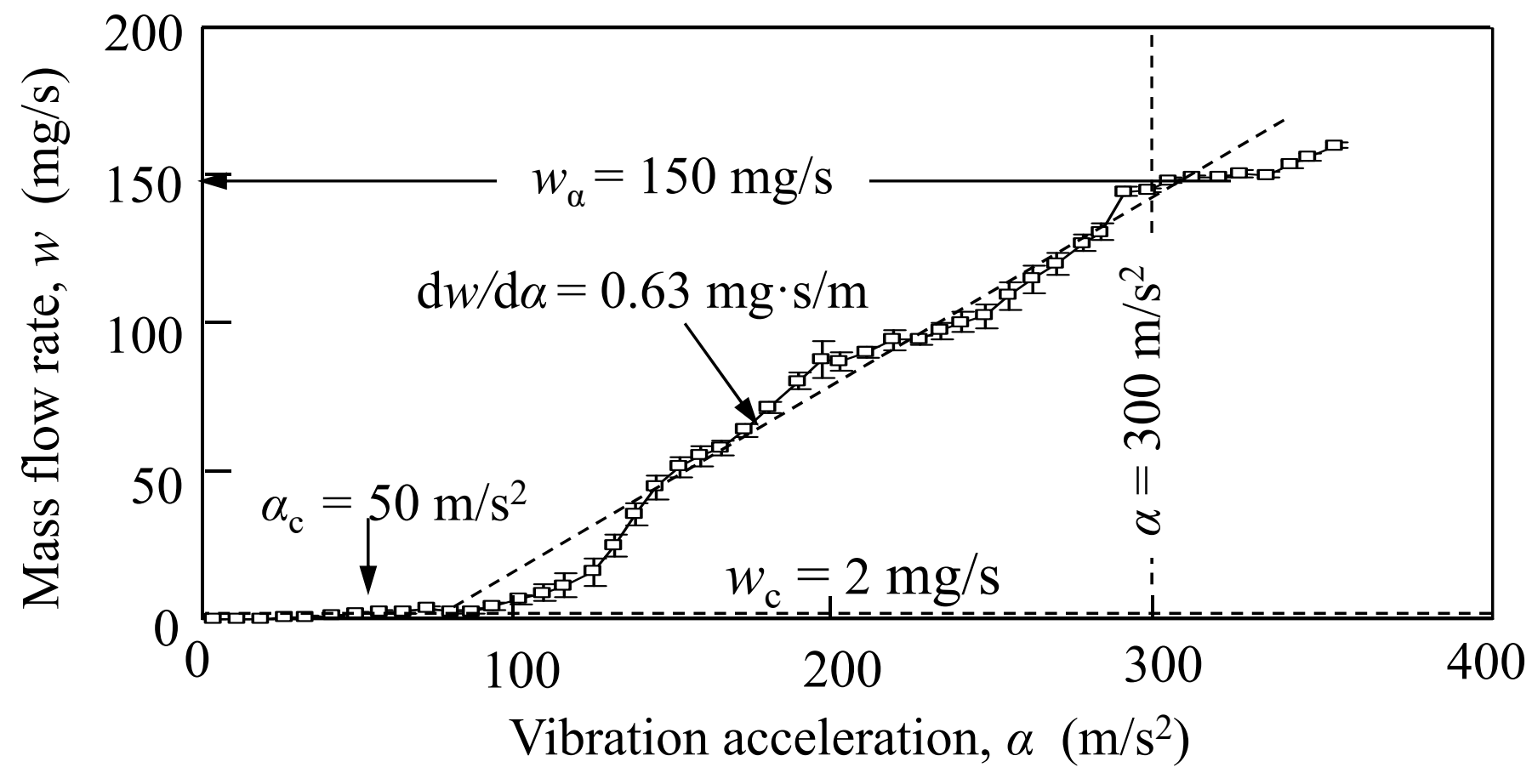

Fig. 4: An example to determine critical vibration acceleration $\alpha_{\mathrm{c}}$ and characteristic mass flow rate $w_{\alpha}$ and gradient of mass flow rate $\mathrm{d} w / \mathrm{d} \alpha$ (flowability profile of $\mathrm{A}(15)$ ). 


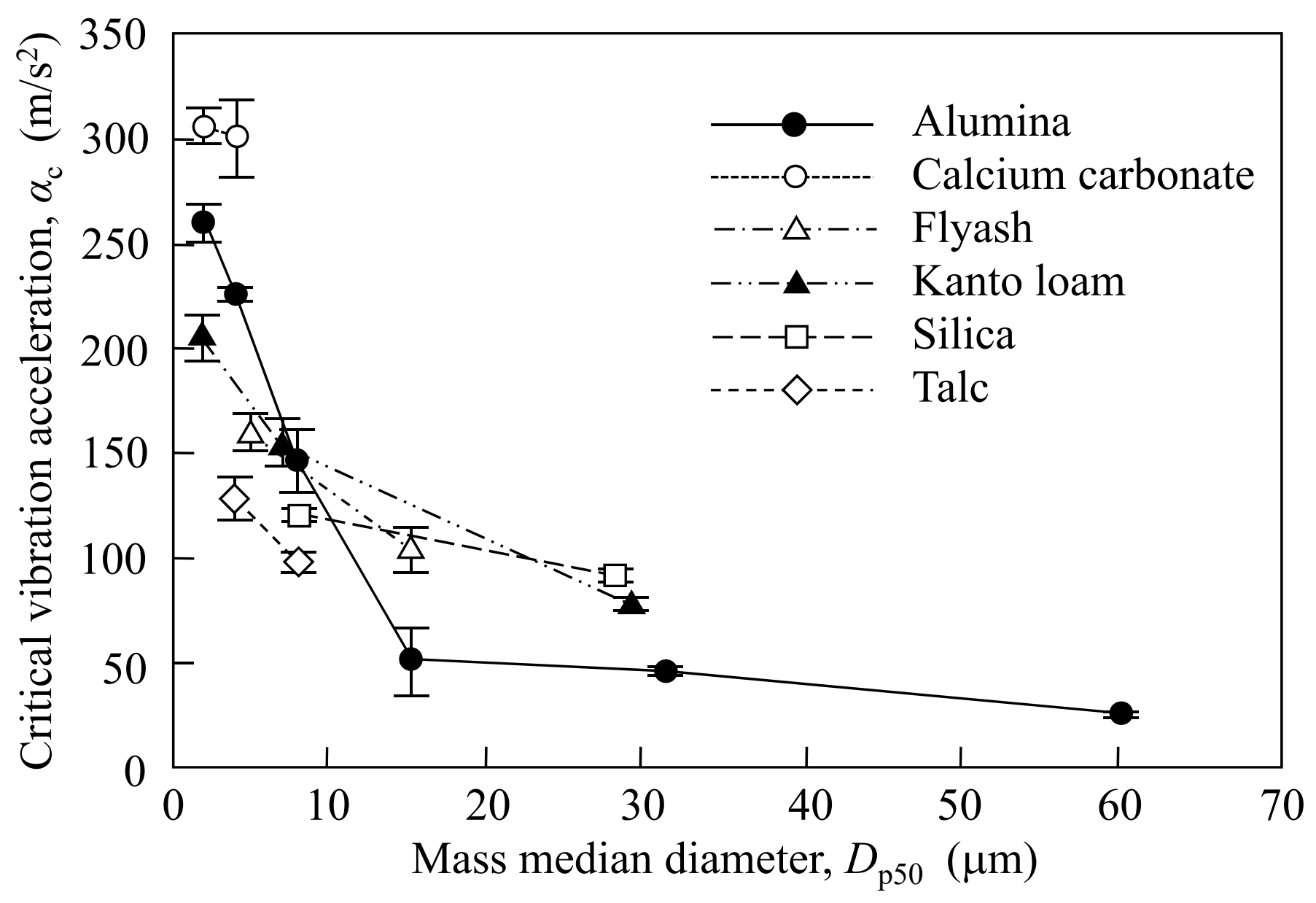

Fig.5: Critical vibration acceleration as a function of the mass median diameter. 


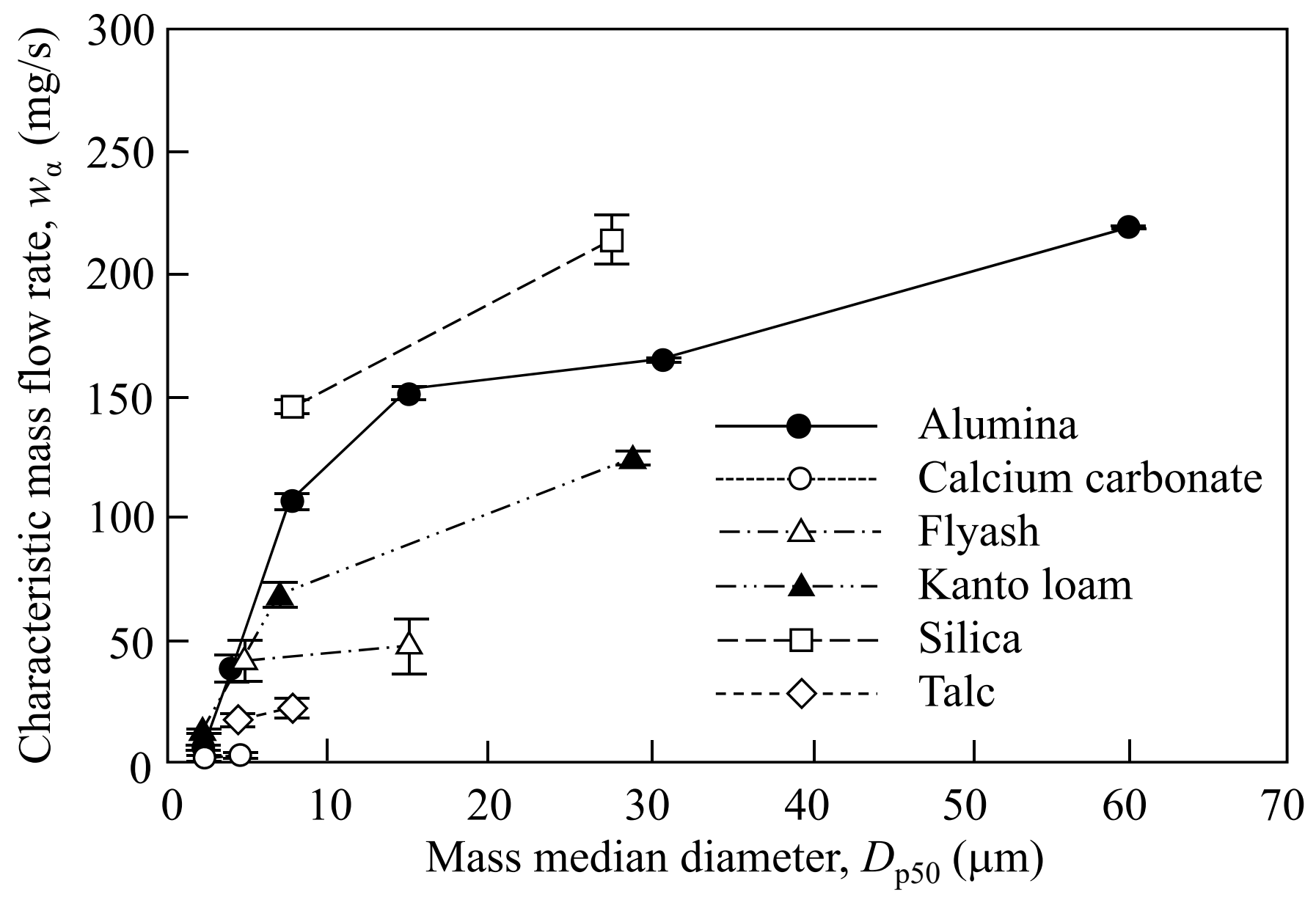

Fig.6: Characteristic mass flow rate as a function of the mass median diameter. 


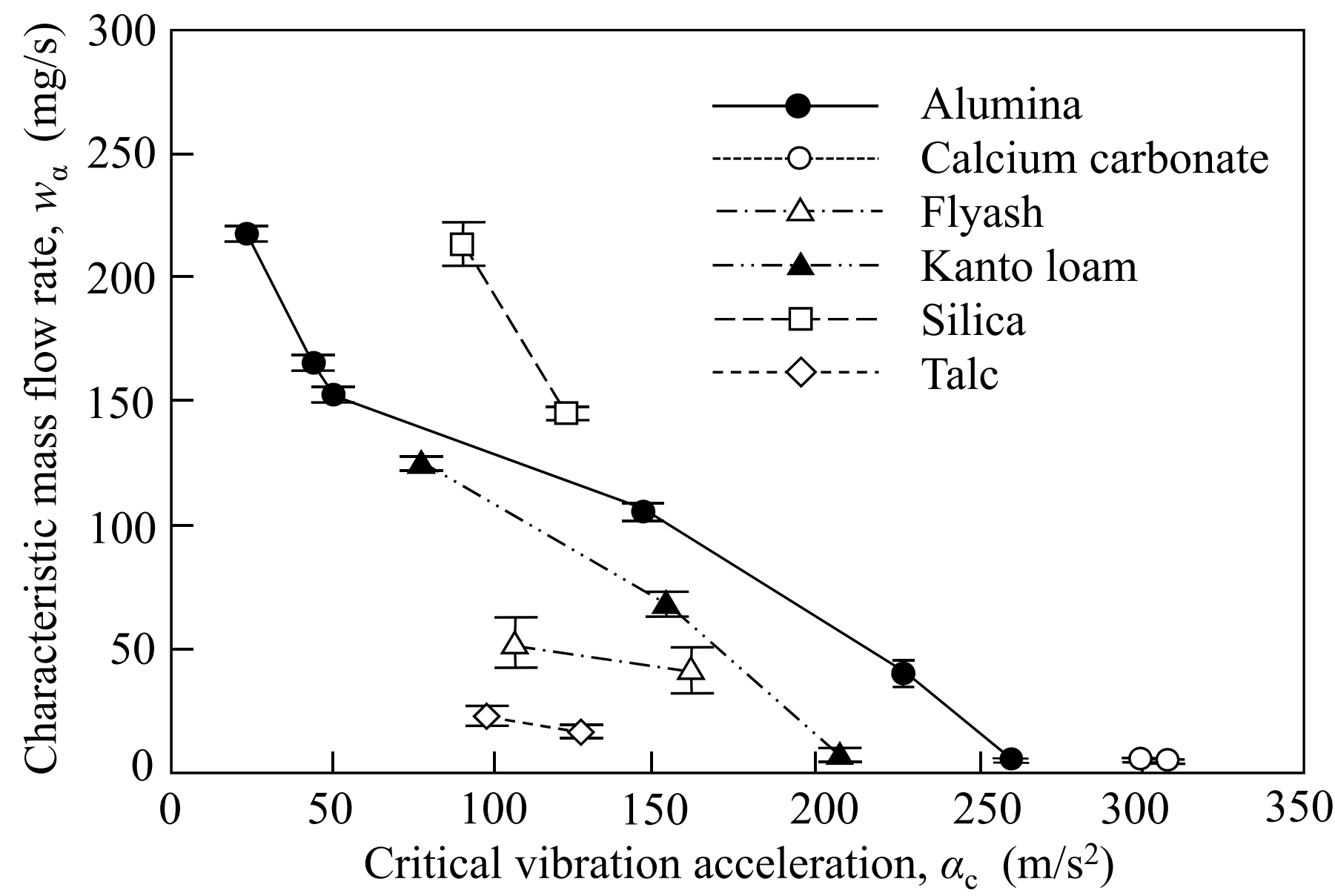

Fig.7: Relationship between the characteristic mass flow rate and the critical vibration acceleration. 


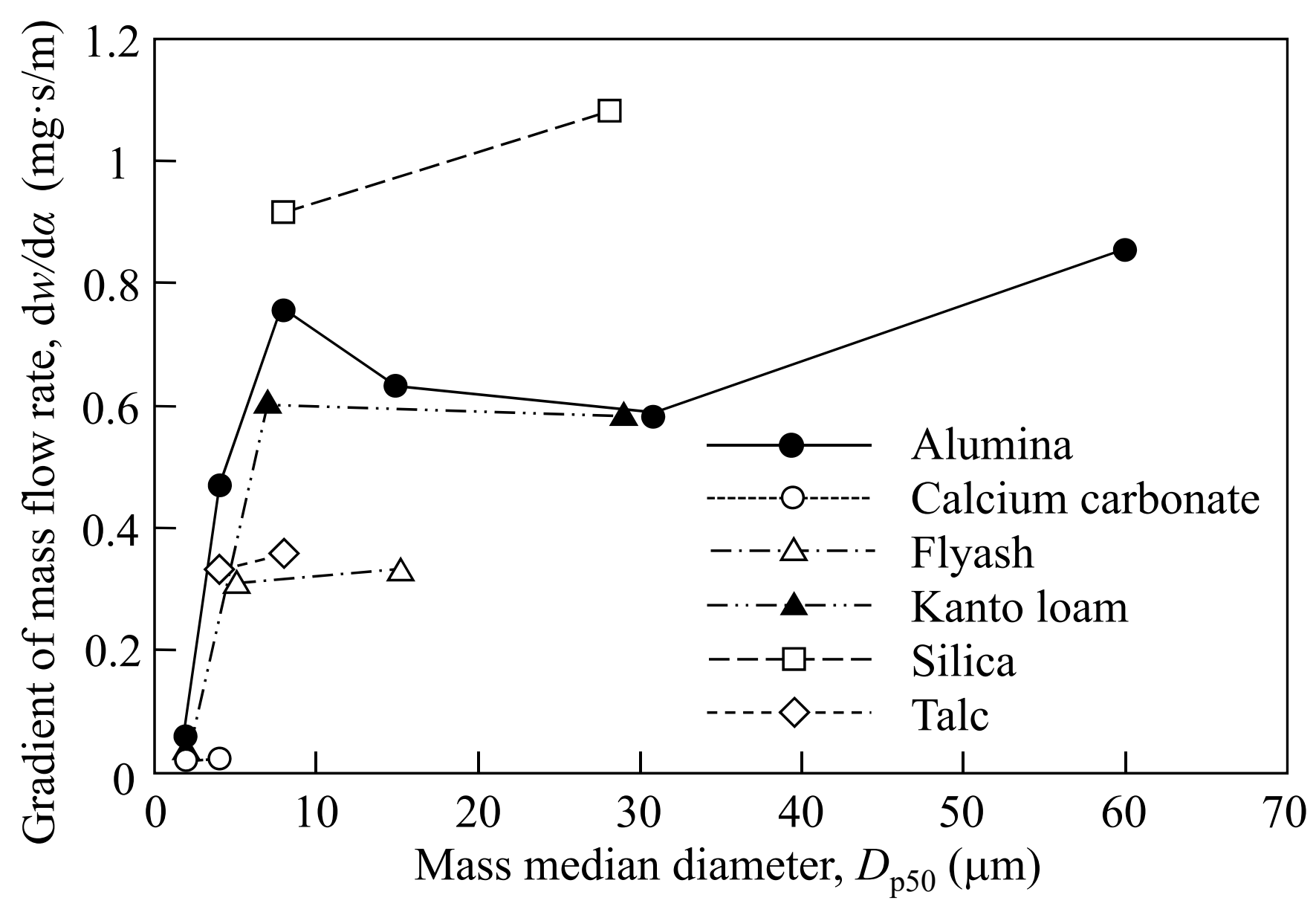

Fig.8: Gradient of the mass flow rate as a function of the mass median diameter. 


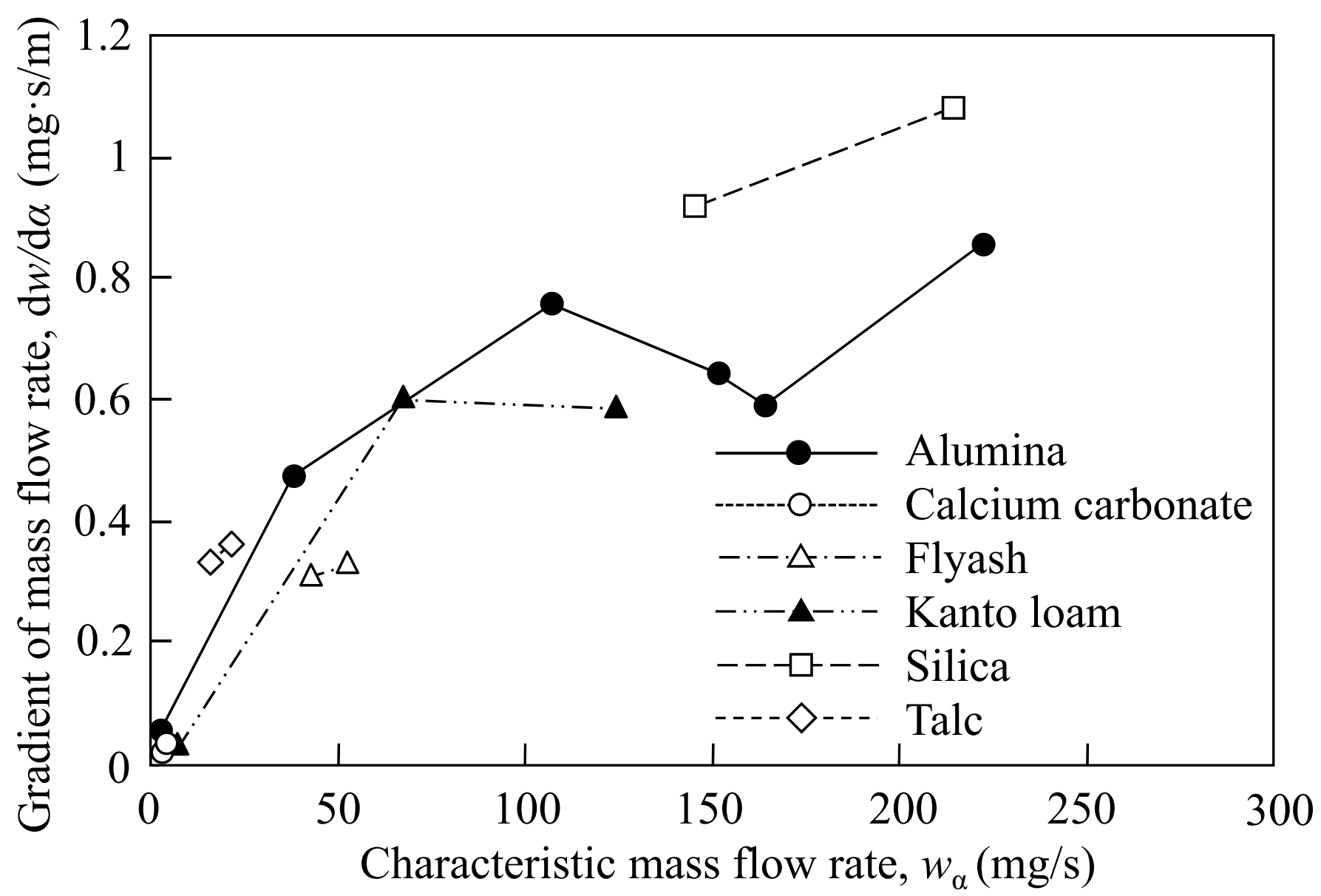

Fig.9: Relationship between the gradient of the mass flow rate and the characteristic mass flow rate. 


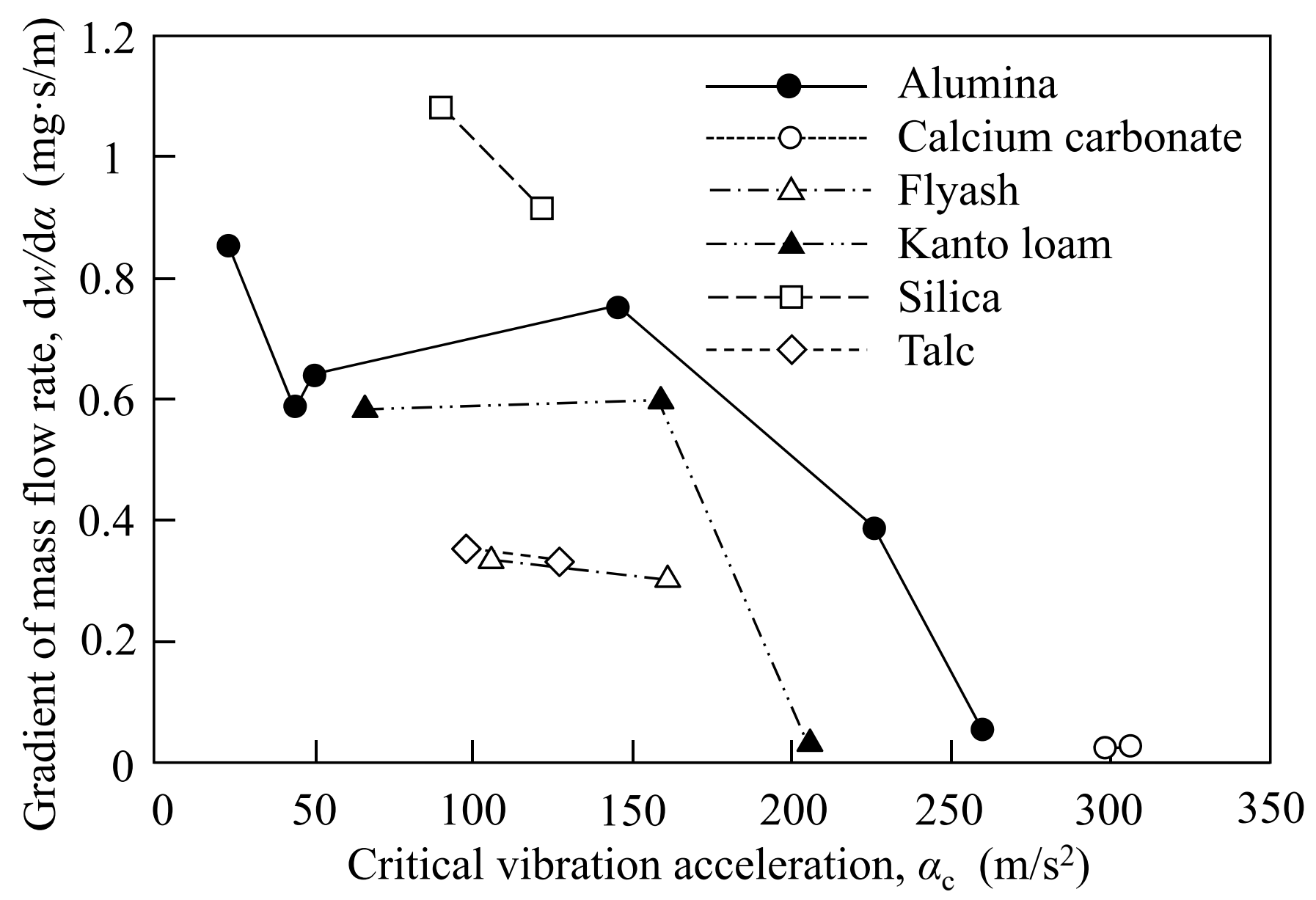

Fig.10: Relationship between the gradient of the mass flow rate and the critical vibration acceleration. 


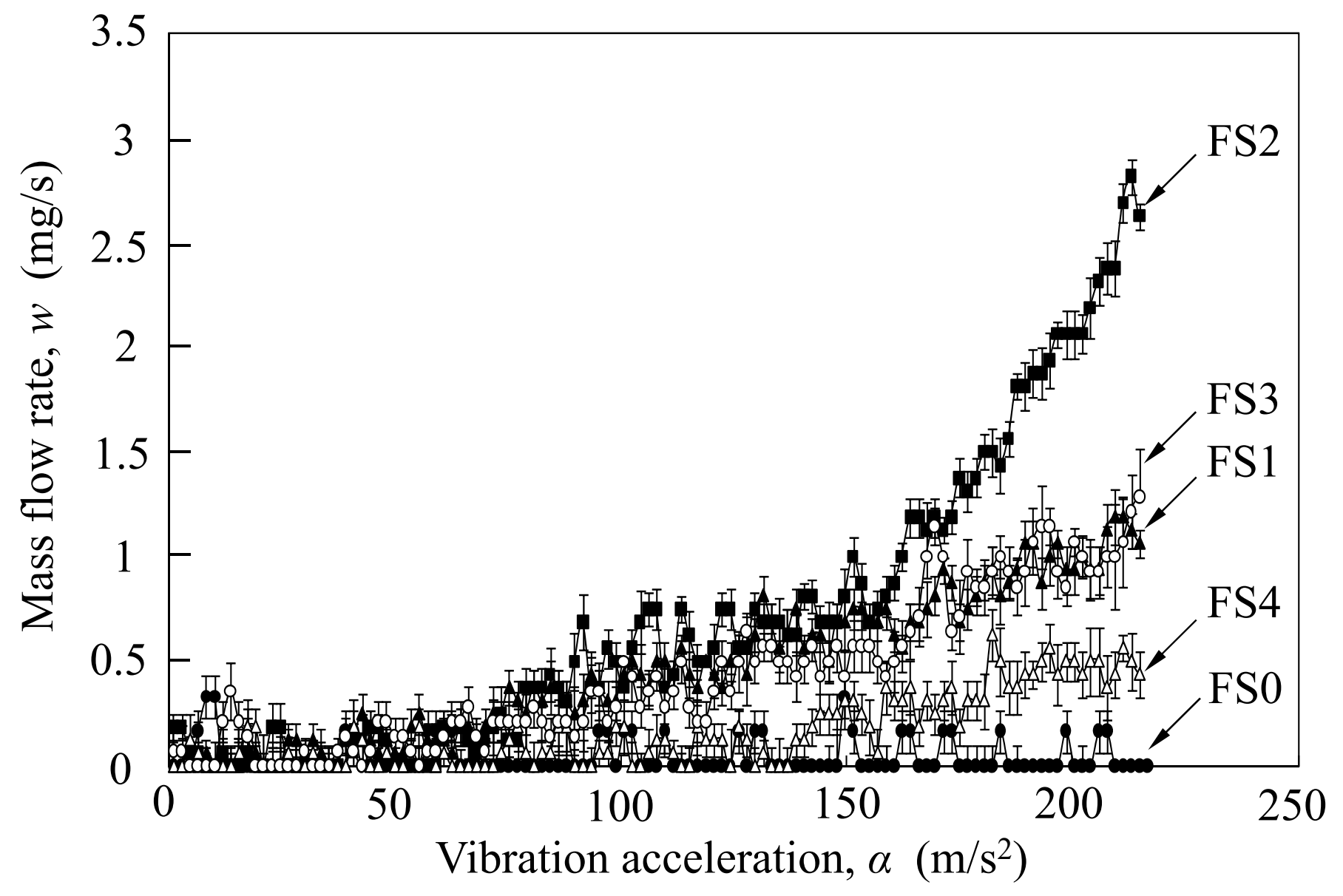

Fig.11: Flowability profiles of fumed silica nanopowders. 